\title{
NOVA-NREL Optimal Vehicle Acquisition Analysis
}

\section{Develop a Vehicle Acquisition Strategy That Maximizes Your Petroleum and Greenhouse Gas Reductions}

Federal fleet managers face unique challenges in accomplishing their missionmeeting agency transportation needs while complying with Federal goals and mandates. Included in these challenges are a variety of statutory requirements, executive orders, and internal goals and objectives that typically focus on petroleum consumption and greenhouse gas (GHG) emissions reductions, alternative fuel vehicle (AFV) acquisitions, and alternative fuel use increases.

Given the large number of mandates affecting Federal fleets and the challenges faced by all fleet managers in executing day-to-day operations, a primary challenge for agencies and other organizations is ensuring that they are as efficient as possible in using constrained fleet budgets.

Consider Figure 1 (page 2), which illustrates that over the past several years, the entire Federal fleet has acquired more than double the required number of AFVs. However:

- More than half of these AFVs will never use alternative fuel due to lack of access to the alternative fuel.

- AFVs often cost more than conventional vehicles, so budget dollars can be squandered if AFVs aren't operated with alternative fuels.

- Federal agencies are struggling to meet petroleum reduction and alternative fuel use increase requirements.

\section{How can fleets make the} best use of limited budgets?
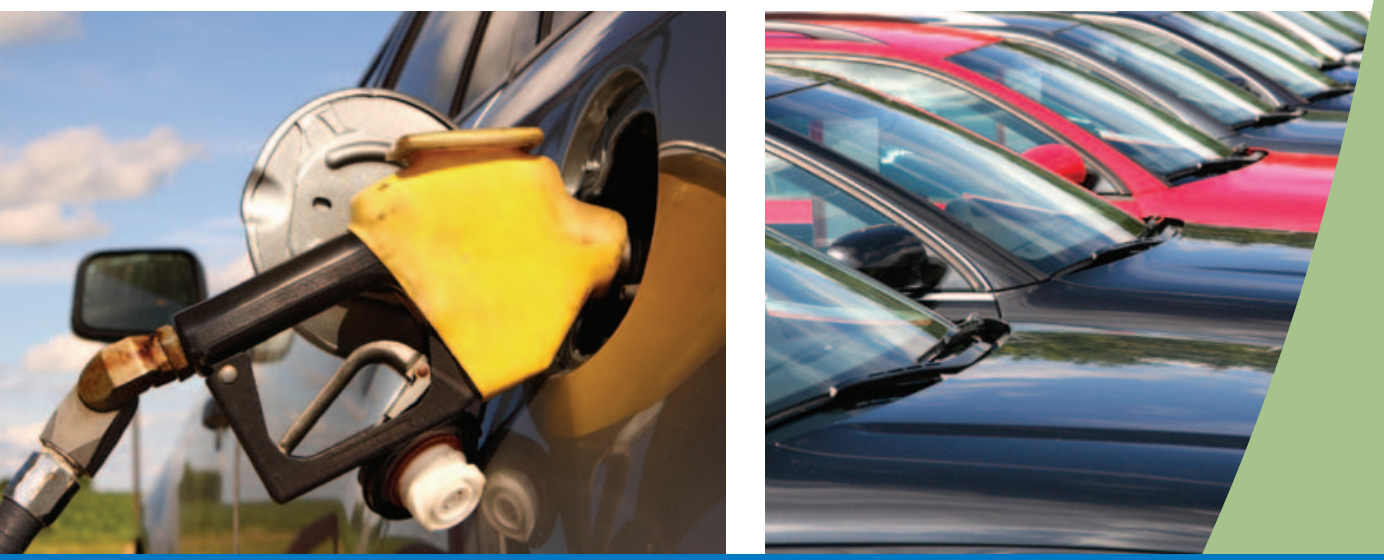

Benefits of a

NOVA Analysis

- Maximize budget: Get a more effective fleet for your money

- Minimize waste: Place the optimal vehicle at the optimal location

- Achieve targets: Efficiently plan for compliance

Mandates That Affect Federal Fleets

- Energy Policy Act (EPAct) of 1992: AFV acquisition requirements

- Executive Order (E.0.) 13423: Petroleum reduction and alternative fuel use increase requirements

- EPAct 2005 Section 701: Required use of alternative fuel in AFVs

- Energy Independence and Security Act (EISA) of 2007 Section 142: Petroleum reduction and alternative fuel use increase plan

- EISA 2007 Section 141: LowGHG-emitting vehicle acquisition requirements

- EISA 2007 Section 246: Installation of renewable fuel pumps at Federal fleet fueling centers

- National Defense Authorization Act (NDAA) of 2008: New AFV definitions

- E.0. 13514: GHG emissions reduction requirement

- Internal, fleet-specific goals and requirements 


\section{EPAct 1992 AFV Acquisition Requirements and Credits}

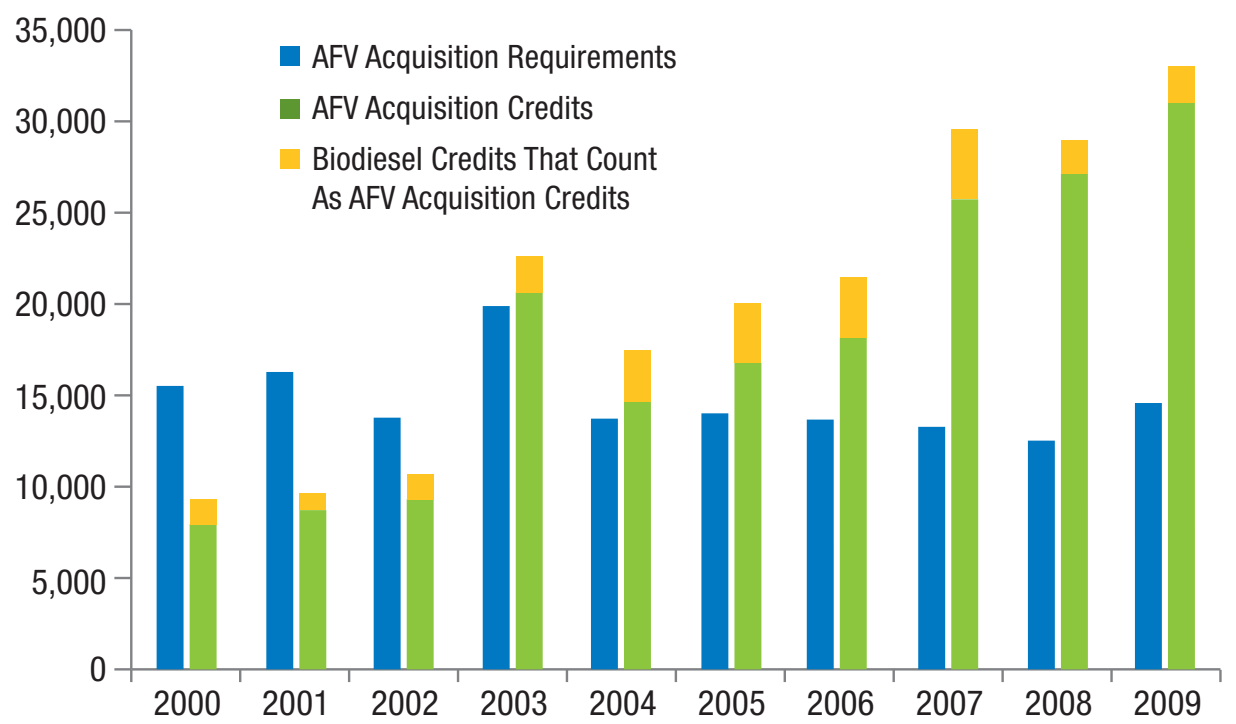

\section{Maximize Fleet Efficiencies With a NOVA Analysis}

An NREL Optimal Vehicle Acquisition — or NOVA — analysis makes use of a mathematical model with a variety of fleet-related data to create an optimal vehicle acquisition strategy for a given goal, such as petroleum or GHG reduction. Figure 2 illustrates major model components, including inputs and constraints.
Figure 1. Federal agency alternative fuel vehicle acquisition requirements and credits from FY 2000 to FY 2009

\section{NOVA ANALYSIS INPUTS}

Specific Vehicle for
Replacement
- Incremental cost
- Type (sedan, SUV)
- Fuel type/use
- Dedicated/dual fuel

Vehicle Data

- Garage locations

- Vehicle info:

- Type of vehicle

- Age

- Annual miles travelled

- Fuel consumption
Fleet Data

- Internal goals and mandates

- Budget constraints

- Replacement criteria

- Potential alternative fuel infrastructure construction

- Types of vehicles/fuels desired, for example:

- Neighborhood electric vehicles (NEVs)

- Compressed natural gas (CNG) vehicles
Fueling Data

- Type of fuel

- Location

- Access

- Alternative fuel station costs (for new construction options)
Figure 2. A NOVA analysis considers vehicle and fleet data to create optimum vehicle acquisition strategies

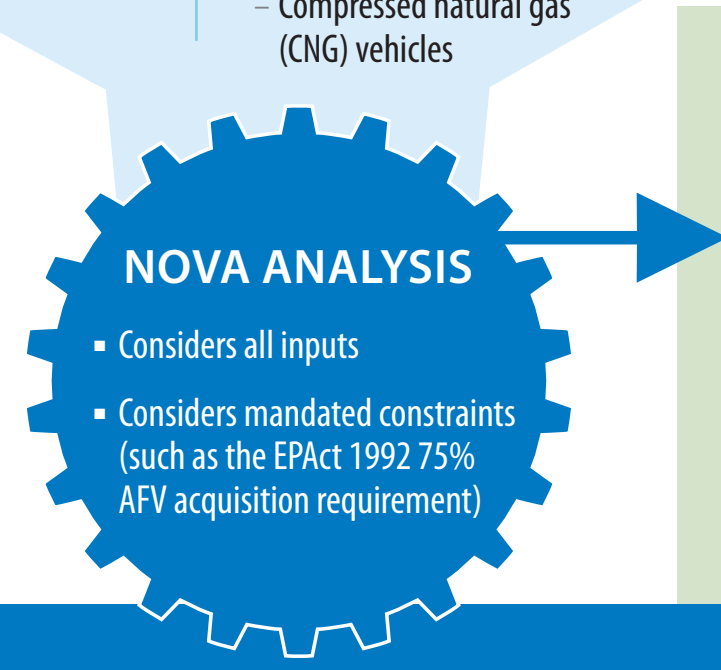

\section{NOVA ANALYSIS OUTPUTS}

- Optimal vehicle acquisition schedule for maximizing petroleum and/or GHG reductions

- Number, location, and type of acquired AFVs - Total money spent

- Alternative fuel availability for acquired vehicles

- Projected petroleum/GHG reductions 


\section{What can a NOVA analysis do for me?}

The following examples illustrate some of the efficiencies a NOVA analysis can help you achieve.

Example 1. As shown in Table 1, Federal Agency A spent $\$ 1.2$ million on incremental AFV costs, but could have met their requirements for less than $25 \%$ of what they spent, according to option 1. Option 2 dramatically increases the percentage of acquired AFVs with access to alternative fuel and funds the retrofitting of nine fuel stations to dispense alternative fuel —at less than $70 \%$ of what was actually spent on just AFVs.

Example 2. The example illustrated in Table 2 compares several potential fleet strategies to what was actually adopted by Federal Agency B. Note that for the same amount of funding expended, petroleum reduction estimates could almost triple, and that petroleum reduction estimates could more than double even if funding were one-tenth of what was spent. Variations between options 1 and 3 and between options 2 and 4 are due to the ability, in some cases, to use funding for alternative fuel infrastructure. In practice, some agencies/entities may not be interested in alternative fuel infrastructure construction. Even without the ability to construct alternative fuel stations, efficiency potentials are very large as illustrated by Figure 3 .
Table 1. Potential Alternative Fuel Access

\begin{tabular}{|l|l|l|l|} 
& Total costs & $\begin{array}{l}\text { AFV } \\
\text { acquisition } \\
\text { requirement } \\
\text { met? }\end{array}$ & $\begin{array}{l}\text { Percentage of } \\
\text { acquired AFVs } \\
\text { with access to } \\
\text { alternative fuel }\end{array}$ \\
\hline Actual results & $\$ 1.2$ million & Yes & $10.6 \%$ \\
\hline Option 1 & $\$ 281,000$ & Yes & $12.5 \%$ \\
\hline Option 2 & $\$ 822,000$ & Yes & $41.3 \%$ \\
\hline
\end{tabular}

Table 2. Potential Petroleum Use Impacts

\begin{tabular}{|l|l|l|l|} 
& Total \$ spent & $\begin{array}{l}\text { \$/gallon } \\
\text { petroleum } \\
\text { reduced }\end{array}$ & $\begin{array}{l}\text { Petroleum } \\
\text { reduction } \\
\text { gallons }\end{array}$ \\
\hline Actual results & $\$ 10$ million & $\$ 64.09$ & 154,137 \\
\hline Option 1 & $\$ 1$ million & $\$ 3.84$ & 260,483 \\
\hline Option 2 & $\$ 10$ million & $\$ 28.40$ & 351,833 \\
\hline Option 3 & $\$ 1$ million & $\$ 2.56$ & 390,638 \\
\hline Option 4 & $\$ 10$ million & $\$ 19.08$ & 523,985 \\
\hline
\end{tabular}

\section{Optimal Petroleum Reduction Without Construction}

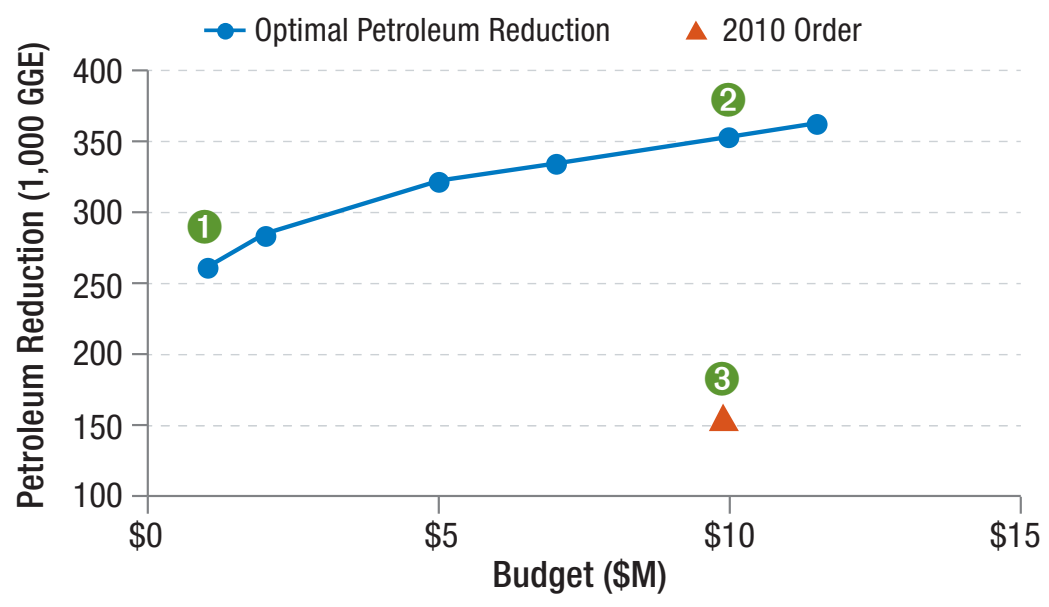

Figure 3. Fleet efficiency potential without adding new alternative fuel infrastructure
Would you rather...

(1) Spend $\$ 1$ million and reduce petroleum consumption by more than 260,000 gallons...

2 Spend $\$ 10$ million and reduce petroleum consumption by more than 350,000 gallons...

(3) Spend $\$ 10$ million and reduce petroleum consumption by only 154,000 gallons.

A NOVA analysis can help you make the right decisions. 
Example 3. A final example focuses on GHG reduction potential. Figure 4 represents actual GHG reduction potential for Federal Agencies C and D in Fiscal Year (FY) 2011, if the agencies were to adopt an optimal vehicle acquisition strategy aimed at maximizing GHG reductions. GHG emission estimates for Agency C's outgoing vehicles are $827.5 \mathrm{CO}_{2}$ ton equivalents, while $\mathrm{GHG}$ emissions for the incoming vehicles are $525.6 \mathrm{CO}_{2}$ ton equivalents - a reduction of more than $36 \%$. GHG emission reduction potential for Agency D's outgoing vehicles is $4,843 \mathrm{CO}_{2}$ ton equivalents, while the $\mathrm{GHG}$ emissions estimated for the incoming vehicles is $3,205 \mathrm{CO}_{2}$ ton equivalentsa reduction of nearly $34 \%$.

\section{Is this analysis only for Federal agencies?}

No, NREL can adapt its analysis to meet other fleet needs.

\section{How is this analysis being used today?}

NREL is using its analysis model to help several agencies plan their FY 2011 vehicle acquisitions, with other agencies lined up to work with NREL in the future.

\section{Are these results typical?}

Yes, for both petroleum and GHG reduction potential; however, these figures represent optimized solutions and should therefore be seen as maximum theoretical estimates. Implementation of recommendations from the analysis is undoubtedly impacted by real-world constraints, which could then be incorporated into subsequent models (if they were not used in the initial models) to better reflect reality and produce achievable petroleum and GHG reductions. Note that additional constraints usually negatively affect petroleum and GHG reduction potential.

My agency has a unique mission or internal constraints. Can I still benefit from the analysis?

Models are continually modified to meet individual customer needs. In one case, a minimum number of hybrid electric vehicles (HEVs) must be purchased; in another case, CNG vehicles are not desired; in a third case, an agency is not interested in funding infrastructure; in almost all cases, agencies are limited to a certain budget. Models can be adjusted accordingly. In many cases, the initial solutions NREL provides to agencies need to be modified slightly to meet unforeseen implementation challenges.

\section{For More Information}

To learn more about an NREL Optimal Vehicle Acquisition analysis, contact Ryan Daley, Federal Fleet Task Lead, at ryan.daley@nrel.gov or 303-275-4466.

\section{Potential GHG Reduction}

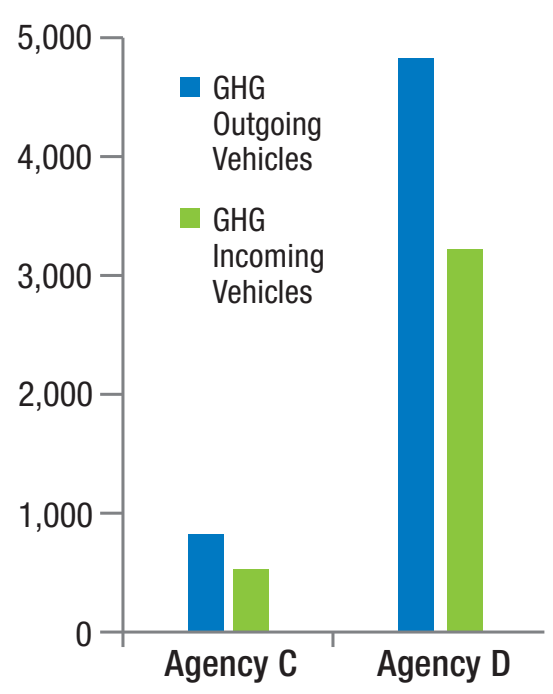

Figure 4. Two Federal agencies' GHG reduction potential in $\mathrm{CO}_{2}$ ton equivalents

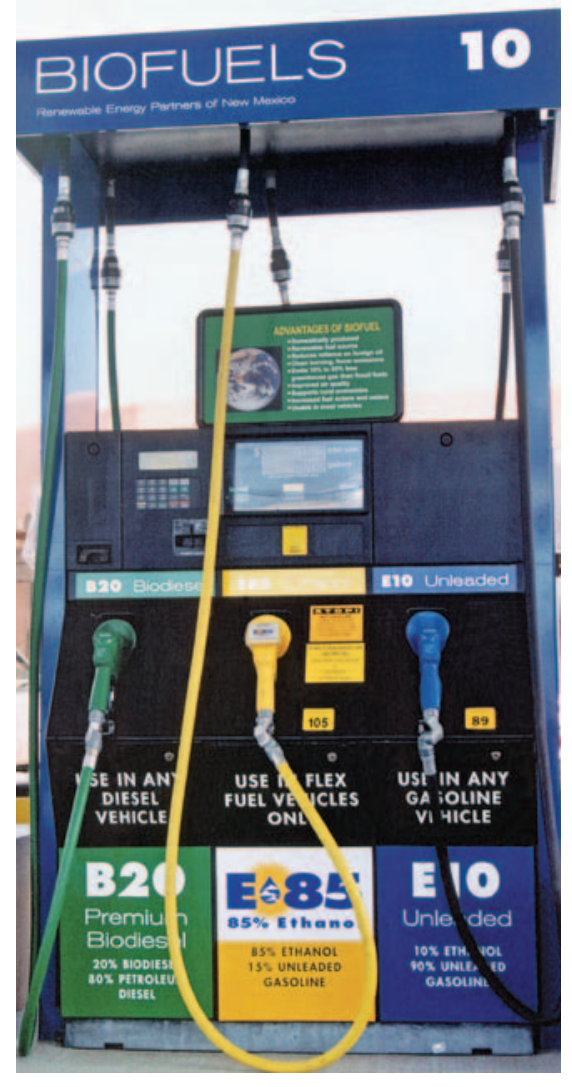

Photo from Charles Bensinger and Renewable Energy Partners of New Mexico, NREL/PIX 13531. 